\title{
What makes travel 'local': Defining and understanding local travel behavior
}

\section{Kevin Manaugh ${ }^{a}$}

McGill University

\author{
Ahmed M. El-Geneidy (corresponding author) ${ }^{\mathrm{b}}$ \\ McGill University
}

\begin{abstract}
In recent years, land use and transportation planning priorities have shifted from issues of mobility to focus on the capacity of neighbourhoods to provide opportunities to live, work, shop, and socialize at the local scale. This research explores a sample of households from Montreal, Quebec, Canada, that engaged in multiple trip purposes on the same day and measures the effects of household, individual, and trip characteristics on their travel behavior, especially the localization of these trips. A new measure to understand the spatial dispersal of actual activity space of each household is proposed while controlling for distance traveled. The findings show that levels of regional and local accessibility have different effects on this new index. Furthermore, these effects vary with household size and sociodemographic factors. This study could help transportation professionals who are aiming to develop policies to localize household travel patterns through land use and transportation coordination at the neighborhood and regional scale. As wealthier car-owning households are seen to exhibit more dispersed travel behavior regardless of accessibility measures, implications for social equity and exclusion are also explored.
\end{abstract}

\section{Introduction}

In recent years, land use and transportation planning priorities have shifted away from issues of mobility to focus on the capacity of a neighbourhood to provide opportunities to live, work, and socialize at the local scale. As planning for accessibility is seen to have more sustainable outcomes, measures of accessibility are gaining popularity as comprehensive performance measures of the interaction between land use and transportation systems (El-Geneidy and Levinson 2006; Grengs, Levine et al. 2010). By favouring shorter travel distances and active modes of transportation, and by influencing household location choices, accessibility can also be used as a sustainability indicator and as a goal in land-use planning. Rather than emphasizing increased road capacity and travel speeds, transportation planners are looking for solutions to increase localized and short-distance travel.

However, there is a potential downside to this framework. Often those whose travel patterns are confined to their local area display this behavior not by choice but because of mobility limitations. In fact, many other reasons may limit individual and household travel patterns, including fear or lack of knowledge about certain areas or destinations and poor or unreliable transit service. Given identical levels of neighbourhood and regional accessibility, we hypothesize that households of differing socioeconomic, attitudinal, and personal preferences might display vastly dissimilar activity spaces. Furthermore, much previous research to understand "local" travel has focused too heavily on either distance traveled or an over-simplified measurement of household activity space. To explore these issues, this study introduces a new measure of the localization of household activity space to help understand the degree to which a household is engaged in local travel. This is done through a new travel behavior index that accounts for the dispersal of household destinations and total distance traveled. The proposed measure provides insight into household activity patterns to help understand the relationship between household activity space and local and regional accessibility while controlling for sociodemographic factors. Therefore, the two main objectives of this paper are (1) to introduce a new measure of the localization of the observed household activity space, and (2) to understand the effects of neighborhood and regional accessibility on this new measure and how these effects vary with socioeconomic and household characteristics. Reaching these objectives is expected to help transportation professionals who are aiming to develop policies to localize household travel patterns through land use and transportation coordination at the neighborhood and regional scale. This paper commences with a brief literature review on the concept of accessibility and household activity space, then continues with a discussion of the methodology and data used in the study. Results of the models are then summarized, followed by a dis-

a kevin.manaugh@mail.mcgill.ca

b ahmed.elgeneidy@mcgill.ca

Copyright 2012 Kevin Manaugh and Ahmed El-Geneidy.

Licensed under the Creative Commons Attribution - NonCommercial License 3.0. 
cussion and a conclusion offering policy recommendations for city and regional planners.

\section{$2 \quad$ Literature review}

Previous research has explored the relationship between accessibility and travel behavior. Examples include Levinson (1998), who looked at the effects of accessibility on the journey to work. Kockelman (1998) studied the effect of various factors on total kilometers traveled and on travel behavior, including accessibility, which she found to have a statistically significant effect on both outcomes. Hanson and Schwab (1987) linked accessibility to characteristics of activity space, finding a small yet significant relationship between the area of activity space and levels of accessibility. Finally, a recent paper examined the dispersal of activities throughout time and space in relation to access to information and communication technologies (ICTs) (Alexander, Ettema et al. 2010). Including accessibility measures at various scales to help in understanding travel behavior and activity space is not new, yet understanding the effects of accessibility at these two levels on the localization of activities is novel in the transportation planning literature. The following section outlines in more detail how regional and local accessibility have been measured and how they are used in travel behavior research.

\subsection{Regional accessibility}

Accessibility is defined as the potential of opportunities for interaction (Hansen 1959) and is often contrasted with mobility (Handy 2002). Accessibility considers the interaction between the land-use and transportation systems and can be used to measure their coordination. Many approaches exist for measuring accessibility, with cumulative opportunities and gravitybased approaches being the most common. This research uses an approach that accounts for competition for jobs, arguably giving a more accurate and nuanced picture of job accessibility. The inverse balancing factors of the doubly constrained spatial interaction model (Wilson 1971) is one of the most commonly used measures that accounts for both the supply and demand side of accessibility. This measure indicates the level of imbalance between the number of opportunities and opportunity seekers (Geurs and Ritsema van Eck 2003). With this measure the supply and demand potential for all of the zones is calculated iteratively, ensuring that the number of trips to and from each zone is equal to the number of opportunities (Geurs and Ritsema van Eck 2003). In other words, it calculates all the potential opportunity-seekers $(E i)$ for the area as well as all the potential opportunities available $(O j)$ and balances the numbers until the model is stable. Using accessibility to jobs and number of potential job seekers, this model can be explained as:

$$
\begin{aligned}
& A_{i m}=\sum_{j=1}^{n} \frac{1}{B_{j}} O_{j} f\left(C_{i j m}\right) \\
& B_{j m}=\sum_{i=1}^{n} \frac{1}{A_{i}} \quad E_{i} f\left(C_{i j m}\right)
\end{aligned}
$$

$A_{i m}$ is the accessibility to jobs for people living in location $i$, using mode $m . B_{j m}$ is accessibility to workers at zone $j$ using mode $m . O_{j}$ is the number of opportunities (jobs) in zone $j$, $E_{i}$ is the number of opportunity-seekers (people) in location $i$, $f\left(\mathrm{C}_{i j m}\right)$ is the impedance function measuring the spatial separation between $i$ and $j$ using mode $m$, and $\mathrm{n}$ is the number of Traffic Analysis Zones (TAZ) in the region.

The first step to operationalize the measure is to calculate the accessibility to jobs for all zones. This involves calculating a gravity measure for all zones. The result of this $A_{i m}$ is incorporated into the calculation of the second factor $B_{j m}(2)$. That result is then incorporated back into the first factor $A_{i m}(1)$ and so on until a balance is reached. The model has converged when the results of two consecutive $A_{i m}$ factors are identical. This study used the 1500 TAZs of the Montreal region to generate the regional accessibility measures.

\subsection{Local accessibility}

Handy (1993) explored issues of local and regional accessibility, identifying neighborhoods in California that display high local but low regional accessibility and vice versa. While the results were somewhat ambiguous, this early study highlights the fact that local accessibility may lead to short local walking but may not affect overall distances travelled to other destinations. Crane and Crepeau (1998) found that neighborhoodlevel characteristics such as street connectivity led to fewer car trips. Surprisingly, land-use mix (measured by the area of commercial land use in the census tract) was seen to lead to more automobile trips in one model but was not significantly associated with mode choice in another model. Dieleman, Dijst et al (2002) found that residents of mixed-use urban areas travel shorter distances and make fewer car trips, yet they utilized a rather oversimplified urban-versus-suburban categorization. Interestingly, their study showed that personal and household characteristics and built-form characteristics have roughly the same explanatory power in the models. Therefore, both small- 
and large-scale measures of accessibility need to be considered when studying travel behavior in urban regions.

Local accessibility can be accounted for through various methods. A recent study comparing a range of walkability indices found the walkscore obtained from walkscore.com (walkscore.com 2010) to be the most reliable measure of predicting walking for shopping purposes (Manaugh and El-Geneidy 2011). Walkscore grants a score between 0 and 100 based on the presence of nearby amenities in 13 separate categories (such as food, cafes, libraries, parks, and cinemas). It uses a simple gravity-based measure to weight nearby locations higher than those more distant. Another recent study (Carr, Dunsiger et al. 2010) also supports the accuracy of the walkscore algorithm. The index is calculated at every postal code in the region and can be used as a measure for neighborhood accessibility. In the Canadian context, a postal code represents a single block-face. It is also more appropriate than the zonal-based system used for the regional measure (Iacono, Krizek et al. 2010).

\subsection{Activity space}

Over the past few decades, the concept of activity space has entered the literature as a manner in which to understand personal and household travel behavior. Activity space has been defined as the geographical area containing all locations an individual has direct contact with as a result of his or her daily activities (Horton and Reynolds 1971). Several studies used data acquired from travel behavior surveys to analyze the spatial representation of individual travel behavior (Newsome, Walcott et al. 1998; Dijst 1999). Activity space has been used in the literature as a measure of travel behavior to better understand travel demand (Newsome, Walcott et al. 1998) and as an indicator of social exclusion (Axhausen and Garling 1992).

Sherman et al. (2005) compared five measures of activity space in a study of healthcare accessibility; the Standard Deviation Ellipse at both 1 and 2 standard deviations, a road network buffer approach, standard time polygon, and relative time polygon. They found that the road network buffer approach is the most accurate and realistic representation of accessibility to healthcare as opposed to the more abstract nature of the standard deviation ellipses. Builiung and Kanaroglou (2006) presented a thorough overview of such approaches, as well as introduced the idea of using convex hull polygons to operationalize activity space.

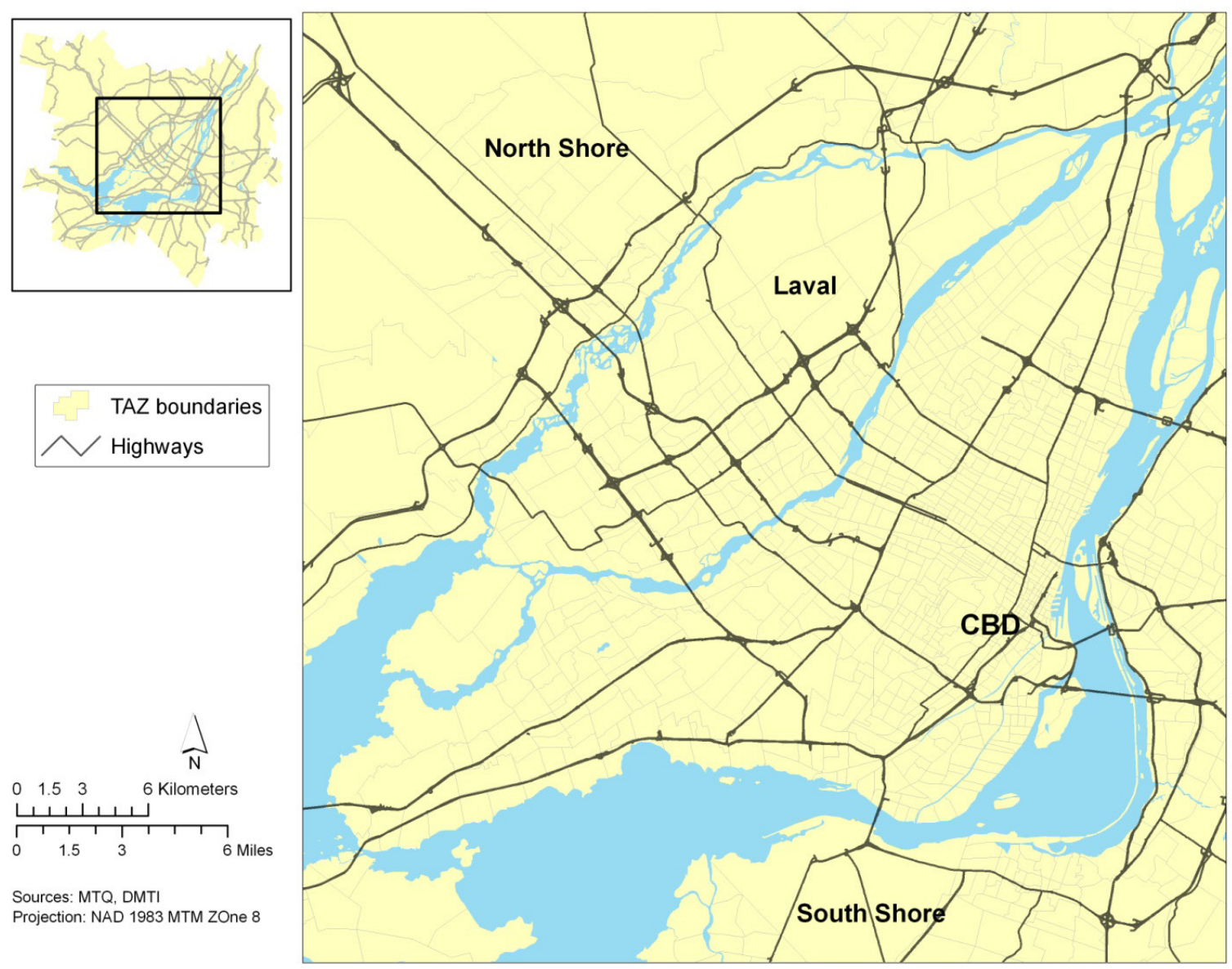

Figure 1: Montreal regional context. 
Activity space can be generated at the individual or household level of analysis. Previous research has shown the importance of examining the household as the main decision-maker entity (Builiung and Kanaroglou 2006). A prior study suggested that individual travel outcomes are heavily influenced by household-level characteristics (Bhat 1996). For these reasons, this study focuses on household-level behavior using the convex hull approach.

Debate exists over the meaning of activity space. Some theories suggest that the size of an activity space can proxy for the social inclusion of a household. Kenyon, along with colleagues, has explored these issues in relating the size of activity spaces to measures of social exclusion (Kenyon, Lyons et al. 2002). However, the prevailing view from an energy/environmental perspective is that smaller, less-dispersed travel behavior is preferable. Accordingly, studying activity space to recommend policies that encourage localized travel patterns requires a distinction between households that travel locally as a result of an amenable local environment and those that travel locally due to a lack of choice.

\section{Study context}

Montréal is among the largest cities in North America. The region covers an area of 4360 square kilometers and had a population of 3.6 million in 2007, with 1.4 million private dwellings, 1.84 million automobiles, and 1.86 million jobs (Communauté Metropolitan de Montréal 2009). The population density in the urbanized area was $1805.1 / \mathrm{km}^{2}$ in 2006 (TAC 2010). Although the city has a vibrant core, the growth at the center has slowed recently in relation to outlying areas (Collin, Dagenais et al. 2003). The region has several employment subcenters (Coffey and Shearmur 2001), meaning that daily travel to the downtown core is not a must for many households. Figure 1 is a map showing the study context. Montreal has a transit modal split above most of North America. The AM peak modal split to the CBD was 59 percent transit, 36 percent automobile, and 4 percent nonmotorized in 2006. Overall modal split was 21 percent, 66 percent, and 12 percent for transit, car, and nonmotorized, respectively. Average vehicle $\mathrm{km}$ per capita was 15.1 , and the median trip-to-work distance was $8.1 \mathrm{~km}$ in 2006 (TAC 2010).

\section{$4 \quad$ Methodology}

The main goal of this paper is to measure the effects of regional and local accessibility on local travel among households throughout the socioeconomic spectrum. Accordingly, the first step is to generate accessibility measures that are theoretically sound at both scales. Regional accessibility is here captured by the inverse balancing factors of the doubly constrained spatial interaction model competition measure (explained above), while local accessibility is measured by the walkscore value. While walkscore has certain issues, it has been shown to be a reliable manner in which to capture the proximity, variety, and ease of access for "everyday" destinations. The second step is to generate activity space and other measures that can be used in measuring the localization of household travel behavior, such as total distance traveled by household and the spatial dispersal of household activity space. A subsample of households from the 2003 Montreal Origin-Destination survey that made both "mandatory" (e.g., work, school) and "non-mandatory" (e.g., leisure, visiting friends, shopping) trips in the same day are analyzed for this purpose (Agence métropolitaine de transport 2003). A new measure of travel behavior that accounts for dispersal of activity space as well as distance traveled is designed.

Elements of household structure play a large role in household travel behavior. Households with more members would be expected to make more trips, travel more total distance, and have a larger activity space. The presence of children in the household is expected to lead to more trips and more spatial dispersion in the travel pattern of the household. To account for variation in household structure, a cluster analysis is conducted. This cluster analysis includes basic household characteristics to account for the variation in households and how their activity spaces vary. Several statistical models are built to explore the relationships between travel behavior of a household while controlling for accessibility measures. Trip purpose dummies are included in the models to control for differences in the types of trips conducted by the household, and household income is included as it is hypothesized that higher incomes could lead to more discretionary travel (Builiung and Kanaroglou 2006).

\section{$5 \quad$ Data sources}

The regional accessibility measure is calculated directly from employment, demographic, and travel time data obtained from the 2006 census conducted by Statistics Canada and Ministère des transports du Québec (MTQ). This measure is generated at the TAZ level of analysis. MTQ provided the research team, with a congested travel time matrix between the TAZs during the morning peak. Yet generating this measure requires calculating gravity-based measures of accessibility to jobs and workers. Calculating the gravity-based measures necessitates a travel-time decay curve, which can be generated 
from combining the travel behavior surveys with travel time obtained from MTQ. The 2003 Origin-Destination (OD) survey (Agence métropolitaine de transport 2003) is used for this purpose. The OD survey is conducted every five years and records completely disaggregated data on each trip made in the respondent's household on the previous workday. The survey is conducted in the autumn, when travel patterns are less affected by either weather conditions or summer school holidays. The precise $\mathrm{X}$ and $\mathrm{Y}$ coordinates of each trip origin and destination is collected along with purpose, mode, and time of each trip; in addition, several socioeconomic variables of both the individual and household are recorded, including age, gender, work status, household income, and number of household members. The postal code of the home address of each household is used to define its level of local accessibility represented by the walkscore obtained from walkscore.com (walkscore. com 2010). A database containing the walkscore of more than 100,000 postal codes in the Montreal region was purchased for use in this study. A spatial join in GIS allowed for the determination of each household's local accessibility with a high degree of accuracy and disaggregation.
The same OD data are used to generate the activity space for household that were involved in several trip purposes during the day in addition to work trips. This resulted in a large sample of 31,333 individuals in 11,633 households making 93,902 trips. First household trips are mapped using the origin and destination coordinates in a GIS environment. Then the Convex Hull application in GIS is used. The convex hull application defines the smallest possible polygon that includes all the household activity points. This polygon corresponds to the household's activity space. The distance traveled used in the analysis is generated by measuring the network distance between every origin and every destination a household member was involved in, solving for shortest travel time based on posted speed limit. This data is obtained from the Montreal OD survey, and the calculations are conducted using the network analyst tools in Esri’s ArcGIS 9.3.

\section{$6 \quad$ Measuring the activity space}

Previous studies used the absolute area of activity space and total distance traveled to estimate how these travel behavior

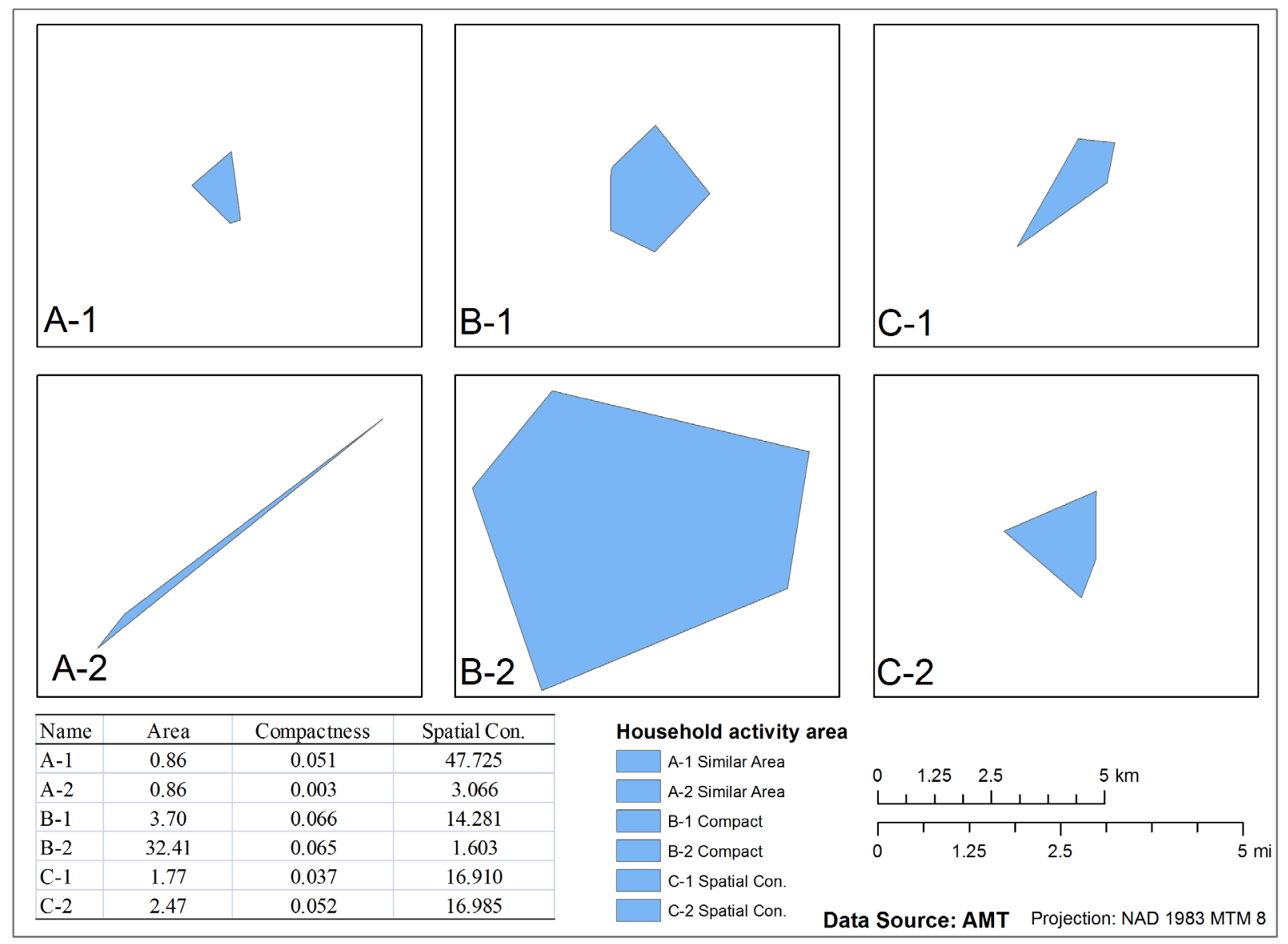

Figure 2: Comparisons between different measures of household activity. 
indicators are affected by urban form and neighborhood characteristics (Newsome, Walcott et al. 1998; Fan and Khattak 2009). However, these measures can be deficient for explaining compact, local travel behavior. The total distance traveled by a household does not account for direction of travel or the resulting use of space. The area of the polygon can be misleading, since having a small area does not necessarily mean having local travel behavior. Figure 2 shows a comparison between various polygons. Polygons A-1 and A-2 have the same area but correspond to two different travel behaviors; A-1 has more trips close to the origin point, while A-2 has a very long trip, but only in one direction. A measure of compactness is used to separate these two travel behaviors (Selkirk 1982). Compactness is the ratio between the area of the polygon and the area of a circle that has the same perimeter, which is known as the circularity ratio.

The measure of compactness is defined as

$$
\operatorname{Comp}=\frac{A_{r}}{p^{2}}
$$

Where Comp is the compactness of the polygon, $A_{r}$ is the area of the polygon, and $P$ is the perimeter of the polygon. Some researchers multiply this value by $4 \pi$ to ensure a value between zero and one. In our case, such multiplication is not necessary. This measure separates households having similar areas with long travel distances from those with short ones, but as shown by polygons B-1 and B-2, this measure does not differentiate between a household with very local activity patterns and ones with more distant ones.

Building on previous work (Parthasarathi, Hochmair et al. 2011) that used the conception of local travel developed by Cerda and El-Geneidy (2010), this study includes both a spatial component of localization along with a network distance traveled to further refine this concept.

To obtain a reliable measure of individual travel activity, the measure of compactness is modified to account for spatial dispersal. The measure of spatial dispersal utilizes area ratios and compactness, generating a bridge between the above-mentioned measures. The spatial dispersal of the activity space can be defined as:

$$
\text { Spatial dispersal }=\frac{A_{r}}{A_{\max }} * \frac{A_{r}}{p^{2}}
$$

Where $A_{r}$ is the area of the activity space of a household, $A_{\max }$ is the area of the largest polygon in the sample, and $\frac{A_{r}}{p^{2}}$ is the compactness of the polygon measured earlier. As seen in Figure 2, polygons C-1 and C-2 have the same level of spatial dispersal as well as a similar area and compactness. A person with a low value of spatial dispersal is expected to live in an area with high levels of regional accessibility. However, this still would not fully describe a household's localized travel, as it does not take into account network distances. Therefore, by generating a simple index of the standardized score for dispersal and total distance traveled, we get a more complete picture. This index is named Local Travel Index (LTI) and can be expressed as:

LTI $=\mathrm{Z}$ score $\frac{A_{r}}{A_{\max }} * \frac{A_{r}}{p^{2}}+$ inverse $\mathrm{Z}$ score $\begin{gathered}\text { (total distance } \\ \text { traveled by } \\ \text { household) }\end{gathered}$

Standardized scores (distance from mean (plus or minus) for a given value) for both dispersal and distance traveled are summed. Standardized scores (Z-scores) allow for a more realistic comparison between households. This composite index is represented by a unit-less number, for which higher values represent household activity spaces that are both spatially concentrated and require short travel distances to generate. As shown in Figure 3, similar spatial dispersal values can be generated by drastically different travel behavior. In the first case (A1 and A2), this is a result of differences in the underlying road network that obligates a traveler to make indirect connections to destinations. In the second case (B1 and B2), the underlying road network is similar in terms of connectivity; however, the observed travel behavior in B2 included many internal trips. While the LTI is a somewhat abstract measurement, we feel that it captures both of the desired inputs to local travel, a measure of total distance traveled and spatial dispersal of destinations. It is also important to note that this measurement is unique to the sample from which the observation is drawn; in other words, these values are relative to all other households in the sample and could not be used across samples. As illustrated in Figure 3, a focus on one or the other could lead to misleading results, since street network characteristics or behavior within the activity space could greatly influence total distance traveled.

\section{$7 \quad$ Cluster analysis}

To gain a better understanding of how socioeconomic factors may influence travel behavior, particularly localization of activity space, a cluster analysis was completed at the household 
level. Basic household characteristics included in the clustering process were income (a categorical variable with a $\$ 20,000$ range), number of cars per licensed driver in household, number of children (under 18 years), number of full-time workers, number of students, and number of seniors. Figure 4 shows the variation from the mean for each of the inputted variables. The number of observations in each cluster is reported on the figure under the cluster name.

To highlight some of the differences, we can look more closely at the wealthy no kids and wealthy large family clusters. Both clusters display household income and car ownership rates above the mean value, yet the number of total household members and number of students is quite different. It is important to note that the OD survey does not collect information on several important sociodemographic factors. For example, we have no information on race, immigrant status, or marital/ relationship status of households.
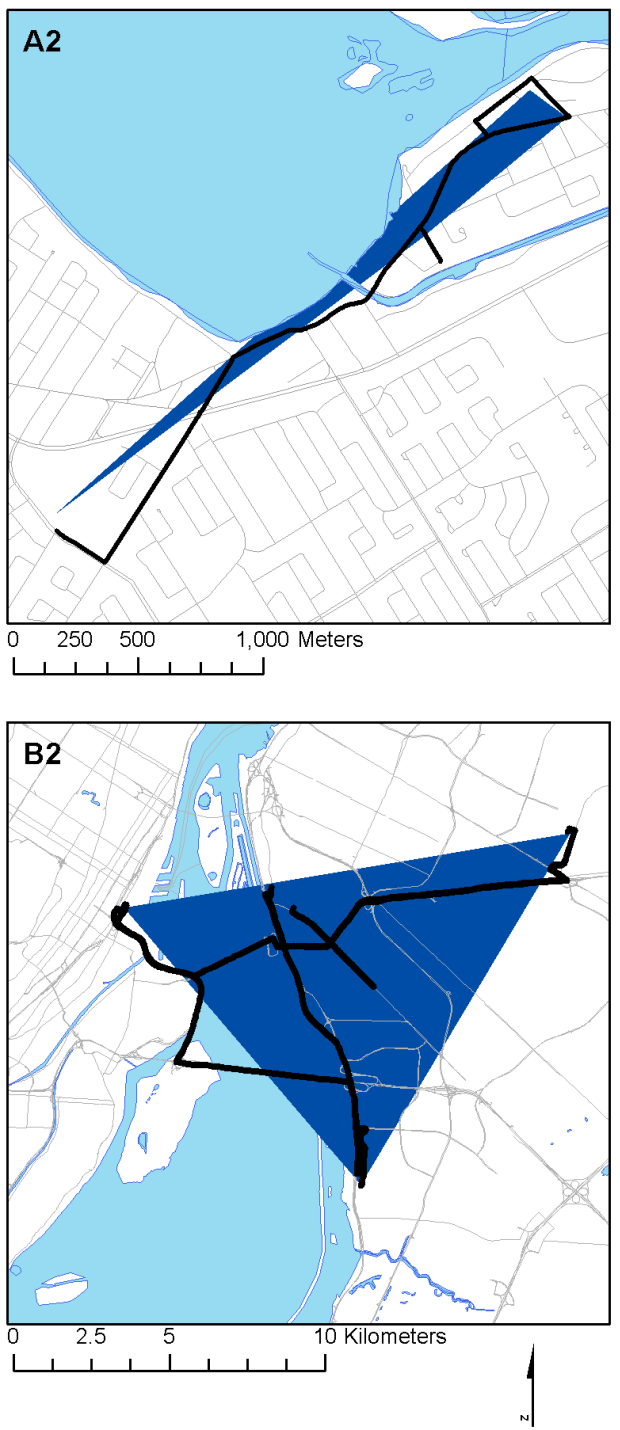

\begin{tabular}{|c|c|c|c|c|}
\hline & A1 & $A 2$ & B1 & B2 \\
\hline Dispersal (z-score) & 0.141 & 0.142 & -0.106 & -0.100 \\
\hline Distance ((z-score) & -1.195 & -1.055 & -0.511 & -0.247 \\
\hline Index & -1.337 & -1.197 & -0.405 & -0.146 \\
\hline
\end{tabular}




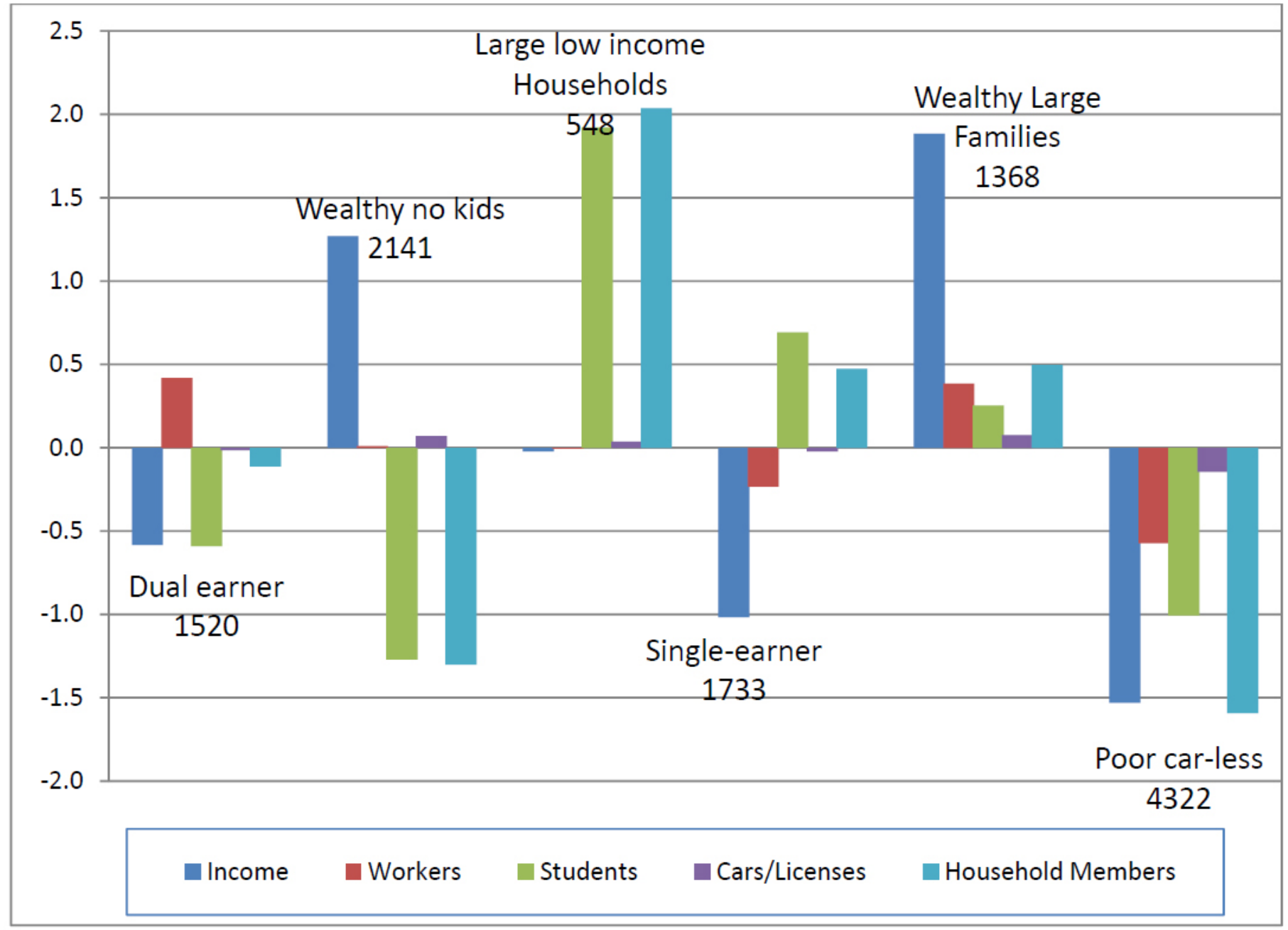

Figure 4: Variation from mean and number of observations for each cluster.

Table 1: Descriptive statistics for all variables in model.

\begin{tabular}{ccccc}
\hline Variable & Mean & Std. Dev. & Min & Max \\
\hline Number of different trip purposes & 2.77 & 0.94 & 2 & 8 \\
Number of trips & 8.07 & 4.09 & 3 & 42 \\
Work trip dummy & 0.92 & 0.27 & 0 & 1 \\
Shopping trip dummy & 0.35 & 0.48 & 0 & 1 \\
School trip dummy & 0.57 & 0.49 & 0 & 1 \\
Leisure dummy & 0.29 & 0.46 & 0 & 1 \\
Social dummy & 0.15 & 0.36 & 0 & 1 \\
Pick up or drop someone off dummy & 0.55 & 1.11 & 0 & 16 \\
Percentage of trips by walking & 11.34 & 21.74 & 0 & 100 \\
Doubly constrained accessibility measure & 14.97 & 11.85 & 0 & 51 \\
Walkscore & 50.82 & 21.42 & 0 & 100 \\
Spatial dispersal & 12.21 & 111.37 & 0 & 5229 \\
Total distance traveled & 51208.80 & 42077.42 & 533.75 & 478794.0 \\
LTI & 0.00 & 1.50 & -48.20 & 8.05 \\
\hline
\end{tabular}


Table 2: Regression results; LTI is dependent variable.

\begin{tabular}{|c|c|c|}
\hline Variable & Coefficient & t-stat \\
\hline Dual-earner households & 0.090 & 0.250 \\
\hline Large low income & $1.262^{* *}$ & 2.140 \\
\hline Single-earner households & $2.740^{* * *}$ & 6.820 \\
\hline Wealthy large families & $-1.871^{* * *}$ & -4.490 \\
\hline Poor car-less & $2.921^{* * *}$ & 10.830 \\
\hline Percentage of trips by walking & $11.310^{* * *}$ & 25.200 \\
\hline Regional accessibility & $0.096^{* * *}$ & 11.470 \\
\hline Local accessibility & $0.159^{* * *}$ & 32.420 \\
\hline Number of different trip purposes & 0.179 & 0.750 \\
\hline Number of trips & $-1.209^{* * *}$ & -30.040 \\
\hline Work trip dummy & $-2.004^{* * *}$ & -4.810 \\
\hline Shopping trip dummy & $1.761^{* * *}$ & 6.100 \\
\hline School trip dummy & -0.504 & -1.550 \\
\hline Social dummy & $-0.785^{* *}$ & -2.320 \\
\hline Leisure dummy & $-0.864^{* * *}$ & -2.970 \\
\hline Pick up or drop someone off dummy & $1.412^{* * *}$ & 4.490 \\
\hline Constant & -1.373 & -2.420 \\
\hline $\begin{array}{l}\mathrm{N}=11633 \text { Reference cluster is "wealthy } \\
\text { no kids" } \\
\text { *** represents significance at } 99 \%,{ }^{* *}= \\
95 \%,{ }^{*}=90 \% \\
\text { Adjusted R-square }=0.416\end{array}$ & & \\
\hline
\end{tabular}

Table 3: Focus on local and regional accessibility effects on activity space. T-values are shown in parentheses.

\begin{tabular}{|c|c|c|c|c|}
\hline Cluster Type & $\begin{array}{c}\text { Walkscore } \beta(\mathrm{t}- \\
\text { value })\end{array}$ & $\begin{array}{l}\text { Regional Acces- } \\
\text { sibility } \beta \text { (t-value) }\end{array}$ & $\begin{array}{c}\mathrm{R} \\
\text { square }\end{array}$ & $\mathrm{N}$ \\
\hline Dual earner & $0.1972(13.49)^{* * *}$ & $0.1104(4.37)^{* * *}$ & 0.296 & 1520 \\
\hline $\begin{array}{l}\text { Wealthy no } \\
\text { kids }\end{array}$ & $0.1661(17.04)^{* * *}$ & $0.1121(6.43)^{* * *}$ & 0.351 & 2141 \\
\hline $\begin{array}{l}\text { Large low } \\
\text { income }\end{array}$ & $0.2048(5.86)^{* * *}$ & $0.1415(2.26)^{* *}$ & 0.241 & 548 \\
\hline $\begin{array}{l}\text { Single } \\
\text { earner }\end{array}$ & $0.1855(12.9)^{* * *}$ & $0.0777(3.04)^{* * *}$ & 0.330 & 1733 \\
\hline $\begin{array}{l}\text { Large } \\
\text { wealthy }\end{array}$ & $0.2573(14.14)^{* * *}$ & $0.1710(5.51)^{* * *}$ & 0.323 & 1368 \\
\hline Poor car-less & $0.0870(15.07)^{* * *}$ & $0.0745(8.01)^{* * *}$ & 0.318 & 4322 \\
\hline
\end{tabular}

\section{$8 \quad$ Statistical analysis}

We developed a set of statistical models to explore the relationship between small, localized activity spaces and accessibility to jobs, workers, and retail. The dependent variable is the LTI explained earlier. Table 1 includes a list and description of the variables used in the analysis as well as summary statistics.

The independent variables have been chosen to explain household characteristics, mobility status, and regional and local accessibility. It is important to note that several other location and accessibility variables were experimented with and subsequently dropped from the analysis because of correlation with other explanatory variables. The models presented in this paper do not include these correlated variables. Interestingly, the local and regional accessibility measures were not shown to be highly correlated (spearman rho=0.4). We hypothesize that the effect of regional and local accessibility will vary by socioeconomic factors. Furthermore, some factors could have complex effects-for example, the presence of school-age children may lead to increased travel distance, though many, if not most, households would try to minimize the dispersal of these trips. Along the same reasoning, picking up and dropping off children or other family members may lead to a decreased time budget so that other trips are simply not possible or must be minimized. Likewise, high accessibility would likely lead to less distance traveled but could generate many shorter trips in different directions-i.e., more dispersed travel.

Table 2 includes the results of an ordinary least square regression model for the LTI measured for households. Both local and regional accessibility measures have a statistically significant positive effect on LTI, with the walkscore having more explanatory power in the model. The types of daily trips made by the household are also noteworthy and have a statistically significant effect in the model. Households that make at least one work trip appear to have a lower LTI, while households that include trips to pick up and drop people off have a "better" LTI than households that do not. Perhaps this is because these household types are restricted in their daily mobility by obligations to either other family members or individuals outside the household. These findings are interesting in that they show that accessibility measures and sociodemographic factors do not alone account for travel behavior; two households with identical accessibility will have varying travel behavior based on what they actually chose to access.

As hypothesized, both local and regional measures of accessibility are shown to affect different types of households in drastically different ways. As shown in Table 3, the coefficients and corresponding t-values are much higher for wealthy households compared to less-wealthy households. Interestingly, re- 
Regional Accessibility

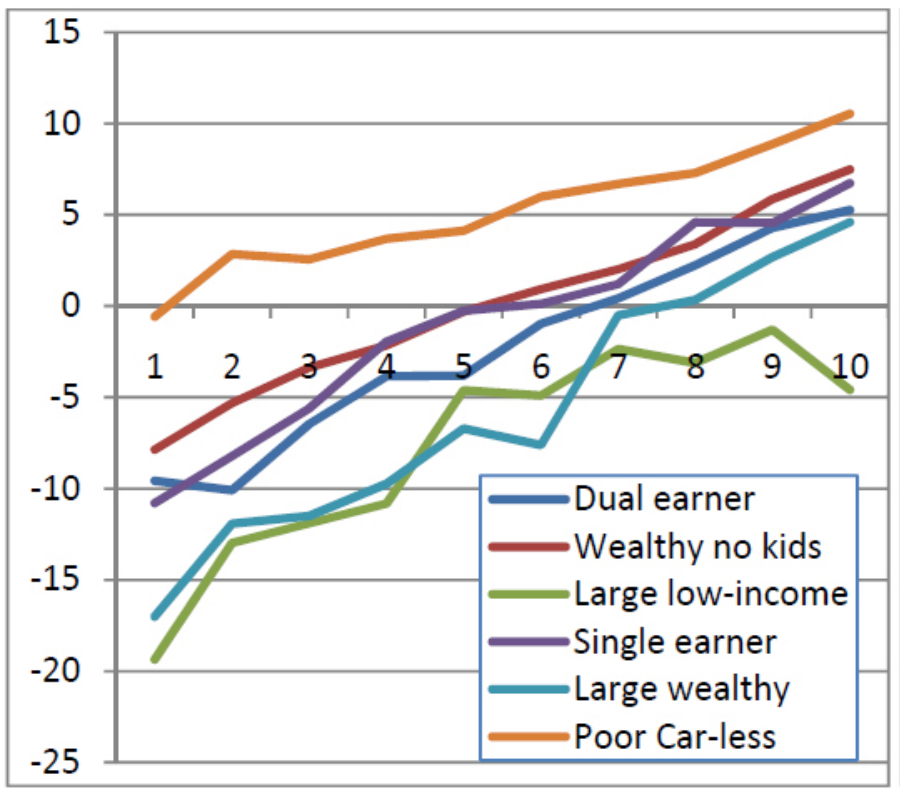

Figure 5: The relationship between regional and local accessibility and LTI. gional job accessibility shows a statistically insignificant correlation for the large low-income household cluster. Past work has found similar results; however, research that only controls for these socioeconomic factors may miss much of the subtlety. Comparing the coefficients for the large wealthy cluster and the poor cluster we see striking differences in the magnitude. We interpret this as showing that household with a high degree of mobility choices (disposable income and car accessibility) are more sensitive to their environment than those with fewer choices. Examining Tables 2 and 3, we can tentatively claim that wealthy large households are both more likely to have larger dispersal of activity space and to be more affected by lo$\mathrm{cal}$ and regional accessibility factors. Conversely, less affluent households will tend to exhibit smaller activity spaces and be less sensitive to changes in their environment. These findings point toward the idea that these issues must be handled delicately; as many poorer households are shown to exhibit smaller activity spaces, perhaps this is not necessarily by choice.

To further illustrate the relationships among accessibility, household types, and LTI values, Figure 4 shows how this generally upward trend is stratified by household type. The $\mathrm{X}$-axis shows the regional and local accessibility decile and the Y-axis is the mean LTI of households observed in this category.

These findings support our hypothesis that levels of local and regional accessibility might impact different types of households with varying degrees of magnitude. While LTI trends upward as levels of accessibility increase, socioeconomic
Local Accessibility

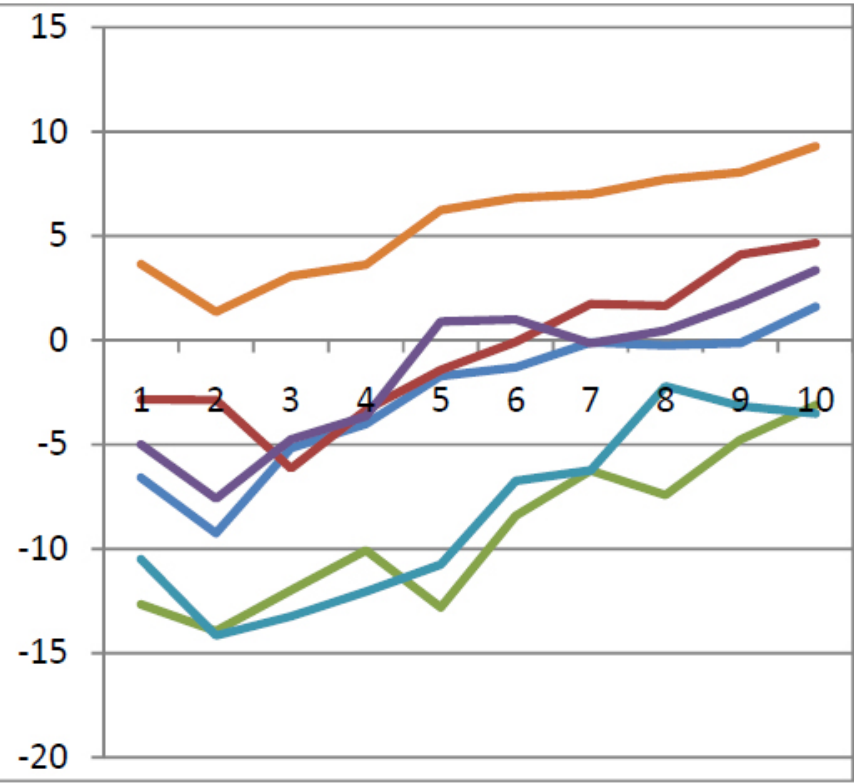

factors, reflected in the household typologies, play a key role. In fact, poorer households show higher LTI values than the wealthy-no kids cluster in all but the highest deciles of accessibility. Interestingly, lower income large households seem to have much more dispersed patterns than other clusters. The contrast between poor car-less households and these large households could be attributable to the high proportion of students in the household; according to the regression results, school trips contribute to a higher dispersal of behavior. In addition, there may be a downward bias in terms of income in households made up of students, who may enjoy parental support or student loans that may not be accounted for in the survey.

\section{Conclusion}

This study explored the relationships among local and regional accessibility, household characteristics, and travel behavior. To study household travel behavior, a new measure of the actual activity space was introduced: Local Travel Index (LTI). The LTI accounts for the compactness and the scale of the activity space as well as the total distance traveled by a household. This measure has proven an effective way to measure the extent to which travel is localized, accounting for network structure.

Regional accessibility is found to have a statistically significant effect on the LTI. This suggests that policies favoring regional accessibility to jobs and workers can lead to more compact and sustainable travel patterns. Higher levels of acces- 
sibility at the regional levels favors more sustainable outcomes such as higher densities, shorter travel distances, and more local, less spatially dispersed travel patterns. Local accessibility measured through the walkscore is found to have a greater impact on LTI compared to regional measures of accessibility. The variation of the explanatory powers of these two measures across household types raises several questions regarding social equity and exclusion. These measures are shown to have much less power on the LTI of poor car-less households, which were already experiencing low LTI. This can be explained as poor car-less households travel locally even if they experience low levels of accessibility to jobs and neighborhood amenities. On the other hand, local and regional accessibility have statistically significant effects on dual earners and wealthy with no kids households, leading to more localized travel.

Our findings suggest that efforts to encourage local travel behavior will ultimately depend on the attitudes and preferences of individuals and households. Wealthier households with high car access are found to be more dispersed and to travel longer distances than poorer households while controlling for number of trips, and, more importantly, local and regional accessibility. This has important implications for both the measurement and understanding of local and regional accessibility factors. Much research, at least implicitly, assumes that most individuals in a region, neighborhood, or household will respond in a similar manner to elements of accessibility. This research shows that household characteristics explain much of the variation in the localization of travel. This would imply that policymakers should take into account local sociodemographic factors when deciding on land-use solutions to minimize longdistance trips.

The primary limitation of this research is the use of a single-day travel survey. A multi-day survey, particularly one that includes weekends, could add much to the findings presented here. Single-day travel diaries miss many important nuances in household travel behavior, and there is no way to ascertain whether the travel exhibited on a given day is "routine" or out of the ordinary. However, the large sample and consistent results lead us to accept the usefulness of the approach presented here.

The focus of the study is to understand - and make an initial attempt to separate - the effects of household characteristics and both local and regional accessibility on local travel behavior. By raising important issues of social equity and justice, it is hoped that this research may direct future research toward these essential elements.

\section{Acknowledgments}

The authors would like to thank Assumpta Cerda for help in generating the accessibility and input during the early stages of this paper. We would like to thank Mr. Pierre Tremblay from the Québec Ministry of Transportation for providing the travel time used in the analysis. We also thank Mr. Daniel Bergeron of the AMT for providing the detailed Montréal OD survey used in the analysis, and Aleisha Jacobson from walkscore.com for providing the walkscores used in the analysis. Last but not least, we would like to thank Prof. Raphael Fischler for his feedback at various stages of this paper. This work was partially funded through an accessibility project funded by Québec Ministry of Transportation and the Le Fonds québécois de la recherche sur la nature et les technologies (FQRNT) and the Natural Science and Engineering Research Council of Canada (NSERC). All opinions in this paper are the responsibility of the authors.

\section{References}

Agence métropolitaine de transport. 2003. Enquête originedestination 2003. Montréal, QC. URL http://www.cimtu. amt.qc.ca/EnqOD/2003/Index.asp.

Alexander, B., D. Ettema, and M. Dijst. 2010. Fragmentation of work activity as a multi-dimensional construct and its association with ict, employment and sociodemographic characteristics. Journal of Transport Geography, 18(1):5564. doi: 10.1016/j.jtrangeo.2009.05.010.

Axhausen, K. and T. Garling. 1992. Activity-based approaches to travel analysis: Conceptual frameworks, models, and research problems. Transport Reviews, 12(4):323-341.

Bhat, C. R. 1996. A generalized multiple durations proportional hazard model with an application to activity behavior during the evening work-to-home commute. Transportation Research Part B: Methodological, 30(6):465-480. doi:10.1016/0191-2615(96)00007-0.

Buliung, R. N. and P. S. Kanaroglou. 2006a. A GIS toolkit for exploring geographies of household activity/travel behavior. Journal of Transport Geography, 14(1):35-51. doi:10.1016/j. jtrangeo.2004.10.008.

Buliung, R. N. and P. S. Kanaroglou. 2006b. Urban form and household activity-travel behavior. Growth and Change, 37(2):172-199. doi: 10.1111/j.14682257.2006.00314.x.

Carr, L. J., S. I. Dunsiger, and B. H. Marcus. 2011. Validation of walk score for estimating access to walkable amenities. British Journal of Sports Medicine, 45(14):1144-1148. doi:10.1136/bjsm.2009.069609.

Cerda, A. and A. M. El-Geneidy. 2010. Understanding the relationships between regional accessibility travel behaviour 
and home values. In 89th Annual Meeting of the Transportation Research Board. Washington, DC. URL http://tram. mcgill.ca/Research/Publications/ACCESS_TRB10.pdf.

Coffey, W. and R. G. Shearmur. 2001. The identification of employment centres in Canadian metropolitan areas: The example of Montreal, 1996. Canadian Geographer / Le Géographe Canadien, 45(3):371-386. doi: 10.1111/j.15410064.2001.tb01188.x.

Collin, J., M. Dagenais, and C. Poitras. 2003. From city to cityregion: Historical perspective on the contentious definitions of the Montréal metropolitan area. Canadian Journal of Urban Research, 12(1):16-34. URL http://ca.vlex.com/vid/ historical- contentious- definitions-53218684.

Communauté Metropolitan de Montréal. Statistics. URL http://www.cmm.qc.ca/index.php?id=334.

Crane, R. and R. Crepeau. 1998. Does neighborhood design influence travel?: A behavioral analysis of travel diary and GIS data. Transportation Research Part D: Transport and Environment, 3(4):225-238.doi: doi:10.1016/S13619209(98)00001-7. URL http://www.ingentaconnect. com/content/els/13619209/1998/00000003/00000004/ art00001.

Dieleman, F. M., M. Dijst, and G. Burghouwt. 2002. Ur-ban form and travel behaviour: Micro-level household at-tributes and residential context. Urban Studies, 39(3):507-527. doi: 10.1080/00420980220112801.

Dijst, M. 1999. Two-earner families and their action spaces: A case study of two Dutch communities. GeoJournal,48(3):195-206. doi: 10.1023/A:1007031809319.

El- Geneidy, A. and D. Levinson. 2006. Access to destinations: Development of accessibility measures. Technical Report MnDOT 2006-16, Minnesota Department of Transportation. URL http://www.cts.umn.edu/Publications/ResearchReports/reportdetail.html?id=1072.

Fan, Y. and A. J. Khattak. 2009. Does urban form matter in solo and joint activity engagement ? Landscape and Urban Planning, 92(3-4):199-209. doi:10.1016/j.landurbplan.2009.05.006.

Geurs, K. T. and J. R. R. van Eck. 2003. Evaluation of accessibility impacts of land-use scenarios: the implications of job competition, land-use, and infrastructure developments for the Netherlands. Environment and Planning B: Planning and Design, 30(1):69-87. doi:10.1068/b12940.

Grengs, J., J. Levine, Q. Shen, and Q. Shen. 2010. Intermetropolitan comparison of transportation accessibility : Sorting out mobility and proximity in San Francisco and Washington, D.C. Journal of Planning Education and Research, 29(4):427-443. doi:10.1177/0739456X10363278.

Handy, S. 1993. Regional versus local accessibility: Implica- tions for network travel. Transportation Research Record, 1400(58-66).

Handy, S. 2002. Accessibility- vs. mobility-enhancing strategies for addressing automobile dependence in the U.S. In European Conference of Ministers of Transport. URL http:// www.des.ucdavis.edu/faculty/handy/ECMTreport.pdf.

Hansen, W. G. 1959. How accessibility shapes land use. Journal of the American Institute of Planners, 25(2):73-76. doi:10.1080/01944365908978307.

Hanson, S. and M. Schwab. 1987. Accessibility and intra-urban travel. Environment and Planning A, 19(6):735-748. doi: 10.1068/a190735.

Horton, F. E. and D. R. Reynolds. 1971. Effects of urban spatial structure on individual behavior. Economic Geography, 47(1):36-48. doi: 10.2307/143224.

Iacono, M., K. J. Krizek, and A. El-Geneidy. 2010. Measuring non-motorized accessibility : issues, alternatives, and execution. Journal of Transport Geography, 18(1):133-140. doi:10.1016/j.jtrangeo.2009.02.002.

Kenyon, S., G. Lyons, and J. Rafferty. 2002. Transport and social exclusion: investigating the possibility of promoting inclusion through virtual mobility. Journal of Transport Geography, 10(3):207-219. doi: 10.1016/S09666923(02)00012-1.

Levinson, D. M. 1998. Accessibility and the journey to work. Journal of Transport Geography, 6(1):11-21. doi:10.1016/ S0966-6923(97)00036-7.

Manaugh, K. and A. El-Geneidy. 2011. Validating walkability indices: How do different households respond to the walkability of their neighborhood? Transportation Research Part D: Transport and Environment, 16(4):309-315. doi:10.1016/j.trd.2011.01.009.

Newsome, T. H., W. A. Walcott, and P. D. Smith.1998. Urban activity spaces: Illustrations and application of a conceptual model for integrating the time and space dimensions. Transportation, 25:357-377. doi:10.1023/A:1005082827030.

Parthasarathi, P., H. Hochmair, and D. Levinson. 2011. Network structure and activity spaces. In 90th Annual Transportation Research Board Conference. doi:10.2139/ ssrn.1736218.

Selkirk, K. E. 1982. Pattern and place: an introduction to the mathematics of geography. Cambridge ; New York: Cambridge University Press.

Sherman, J., J. Spencer, J. Preisser, W. Gesler, and T. Arcury.2005. A suite of methods for representing activity space in a healthcare accessibility study. International Journal of Health Geographics, 4(1):24. doi: 10.1186/1476072X-4-24.

Transportation Association of Canada. 2010. Urban transpor- 
tation indicators-fourth survey. Technical report, Transportation Association of Canada. URL http://www.tacatc.ca/ english/resourcecentre/readingroom/pdf/uti survey4.pdf.

Walk Score. 2010. URL http://www.walkscore.com.

Wilson, A. G. 1971. A family of spatial interaction models and associated developments. Environment and Planning A, 3(1):1-32. 